\title{
CDISC SDTM Reproductive System Findings Test Code Terminology
}

National Cancer Institute

\section{Source}

National Cancer Institute. CDISC SDTM Reproductive System Findings Test Code

Terminology. NCl Thesaurus. Code C106479.

Terminology associated with the reproductive system findings test code codelist of the Clinical Data Interchange Standards Consortium (CDISC) Study Data Tabulation Model (SDTM). 